\title{
Physician-writers in the age of blogging
}

Previously published at www.cmaj.ca on Aug. 3, 2009.

I $\mathrm{n}$ a recent Salon article, Baerlocher and Detsky ${ }^{1}$ argue that while the debate between free speech and professional responsibility is an important one, the main reason that physicians should be reluctant to blog is simple selfprotectionism: posting personal material, including narratives about patients, online may leave a physician vulnerable.

There is, however, another reason for reluctance: the underlying ethics. This involves drawing the line between physicians' right to freedom of expression, and their responsibility to their patients and their profession. Blogging is easy, fast and increasingly popular. However, some cyber cowboys, seem to think they are exempt from the rules that govern print publication. This is not the case. ${ }^{2}$ And for physician writers, these rules include respecting patient confidentiality.

Some might argue that this ethical responsibility impinges upon the physician's right to freedom of speech and self-expression. This is not entirely so, but boundaries must be set: revealing confidences violates standards of confidentiality unless explicit permission is given, or the story and characters are fictionalized so that the patient cannot self-identify. The exploitation of patients for their stories is clearly inappropriate, and alters the physicianpatient relationship in such a way that it becomes instrumental: the patient becomes a means to a narrative.

Stories penned by physicians range from those that recount actual patient encounters (which are clearly patient owned) to those that are purely fictional (which are clearly physician owned). At the former end of this spectrum, it is clearly the patient who has a vested interest in the fabric of the narrative without the patient, after all, this story would not exist. In essence, the story belongs to this patient, and to share it without valid consent would clearly be to violate confidentiality. At the latter

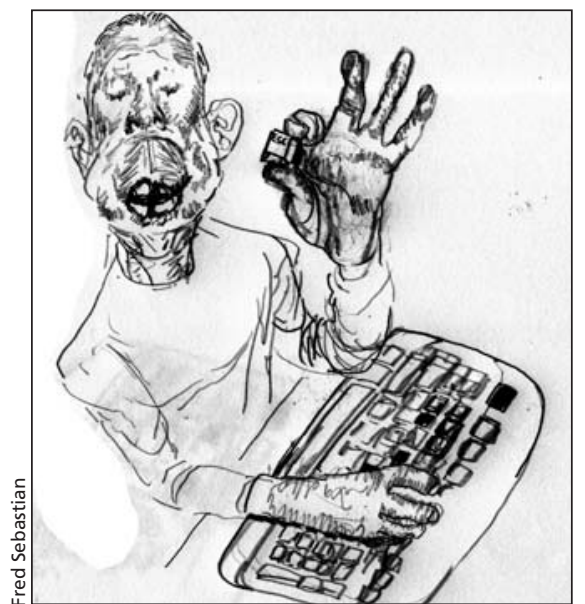

end of the spectrum lie those stories that are entirely products of the imagination, and one would be hard-pressed to attribute ownership of these to anyone but the physician.

Between these 2 extremes lies a vast grey area that further complicates the ethics of narrative medicine. There are stories that are largely fictional, but are inspired in part by actual clinical events, a style of narrative known colloquially as "imaginative truth." There is also uncertainty in the realm of physician autobiographies, particularly when it is clear that certain patients and encounters have had a profound impact on one's practise of medicine (or attitudes toward life in general). It may be difficult to separate the variable degrees of ownership of the physician and patient, even as the latter may play either a central or a peripheral role in the reflections of the former.

Further, the stipulation that all narratives that involve patients must be vetted by those patients would effectively serve to limit those stories to "agreeable patients, successful outcomes, and satisfied physicians." ${ }^{\prime 3}$ One might rationalize that less-palatable themes could be dealt with in fiction but ultimately, a physician's story is unlikely to be wholly fictional. Indeed, there is an expectation of truth from readers, who naturally assume that the narrative draws on the personal experience and attitudes of its author. By and large, they are correct. The physi- cian-as-author is vulnerable to the "professionalist assumption," whereby his credentials implicitly direct the reader to assume a modicum of truth in his narrative. This is particularly true in blogs, which are often diary-like.

The other potential obstacle for the physician-writer concerns his responsibility to his profession. While the individual physician may be unconcerned about his own public or private reputation as a result of his musings, blogs have the potential to taint the public perception of the profession. A simple veneer to mask patient information does not fully answer this extraordinary challenge - and neither does the practice of fictionalizing stories to protect individual patients.

As the Internet continues to develop as a forum for the physician-writer, discussions of the ethics of such practices will become increasingly relevant. There must be a careful balance between the not-insignificant right of the physician to freedom of self-expression and the essential rights of patients to confidentiality. It may be enough to say that blogging, despite its accessibility, should be approached no differently than publication in more traditional media. Until more comprehensive professional guidelines evolve regarding the place of narrative writing within medicine, it is prudent to err on the side of caution.

\section{Christopher Dainton MD}

Family practice resident

Toronto, Ont.

\section{REFERENCES}

1. Baerlocher MO, Detsky AS. Online medical blogging: don't do it! CMAJ 2008;179:292.

2. Arant MD, Anderson JQ. Newspaper online editors support traditional standards. Newspaper Research Journal 2001; 22.

3. Coulehan J, Hunsaker-Hawkins A. Keeping faith: Ethics and the physician-writer. Ann Intern Med 2003;139:307-11

Have you got an opinion about this article? Post your views at www.cmaj.ca. Potential Salon contributors are welcome to send a query to salon@cmaj.ca 